\title{
GCU
}

Glasgow Caledonian

University

University for the Common Good

\section{Effects of creep recovery on the fracture properties of concrete}

\author{
Li, Jie; Dong, Wei; Zhang, Binsheng; Zhou, Xiangming
}

Published in:

Theoretical and Applied Fracture Mechanics

DOI:

10.1016/j.tafmec.2020.102694

Publication date:

2020

Document Version

Author accepted manuscript

Link to publication in ResearchOnline

Citation for published version (Harvard):

$\mathrm{Li}, \mathrm{J}$, Dong, W, Zhang, B \& Zhou, X 2020, 'Effects of creep recovery on the fracture properties of concrete',

Theoretical and Applied Fracture Mechanics, vol. 109, 102694. https://doi.org/10.1016/j.tafmec.2020.102694

\section{General rights}

Copyright and moral rights for the publications made accessible in the public portal are retained by the authors and/or other copyright owners and it is a condition of accessing publications that users recognise and abide by the legal requirements associated with these rights.

Take down policy

If you believe that this document breaches copyright please view our takedown policy at https://edshare.gcu.ac.uk/id/eprint/5179 for details of how to contact us. 


\section{Effects of creep recovery on the fracture properties of concrete}

\section{Jie Li ${ }^{\mathrm{a}}$, Wei Dong ${ }^{\mathrm{b}, *}$, Binsheng Zhang ${ }^{\mathrm{c}}$, Xue Zhang ${ }^{\mathrm{d}}$}

3

4

5

6

7

8

9

10

11

12

13

14

15

16

17

18

19

20

21

22

23

24

25 26

27 8 9 0 1 2 3 24 5 27

${ }^{a} \mathrm{PhD}$ student, State Key Laboratory of Coastal and Offshore Engineering, Dalian University of Technology, Dalian 116024, P. R. China. E-mail: ngdlj2013@163.com

${ }^{\mathrm{b}}$ Professor, State Key Laboratory of Coastal and Offshore Engineering, Dalian University of Technology, Dalian 116024, P. R. China.

*Corresponding author, E-mail: dongwei@dlut.edu.cn

${ }^{\mathrm{c}}$ Professor, Department of Civil Engineering and Environmental Management, School of Computing, Engineering and Built Environment, Glasgow Caledonian University, Glasgow G4 0BA, Scotland, United Kingdom. E-mail:

\section{Ben.Zhang@gcu.ac.uk}

${ }^{\mathrm{d}}$ Associate Professor, State Key Laboratory of Coastal and Offshore Engineering, Dalian University of Technology, Dalian 116024, P. R. China. E-mail: Xuezhang@dlut.edu.cn 


\section{ABSTRACT}

To study the influence of creep recovery on the fracture properties of concrete, the pre-notched specimens were firstly subjected to three-point bending (TPB) loading at $60 \%$ peak load $\left(P_{\max }\right)$ over 30 days. Afterwards, the load was removed and the creep recovery tests were performed for 1, 2, 3 and 15 days, respectively. Thereafter, the quasi-static TPB tests were conducted on the creep recovery specimens. The deformation versus time curves, initial cracking load $\left(P_{\text {ini }}\right)$, peak load and fracture energy in the quasi-static TPB tests after creep recovery were obtained. Also, the numerical analyses were conducted by combining with the Norton-Bailey model to investigate the stress variations at the crack tip and the time-dependent behaviour of concrete. By comparing the fracture parameters for the specimens with and without undergoing creep recovery, the effects of creep recovery on the fracture characteristics of concrete were assessed. The results showed that during the creep stage, the stress relaxation generated at the crack tip due to viscoelastic characteristics of concrete enlarged the deformation. In contrast, the reversed stress would occur at the crack tip during the recovery stage, and its relaxation over the time contributed to the time-dependent deformation during the creep recovery stage. By comparing with the specimens under the quasi-static TPB loading, $P_{\text {ini }}$ and $P_{\max }$ for the creep recovery specimens would increase, and the increments slowed down over the recovery time. However, the increases in $P_{\text {ini }}$ and $P_{\max }$ for the creep recovery specimens could not enhance the initial and critical fracture toughnesses and these toughnesses were approximately equal to those under the quasi-static tests.

Keywords: Concrete; Fracture properties; Creep recovery; Stress relaxation; Initial fracture toughness; Critical fracture toughness 


\begin{tabular}{|c|c|}
\hline \multicolumn{2}{|l|}{ Nomenclature } \\
\hline$A$ & empirical constant \\
\hline$a_{0}$ & notch depth \\
\hline$a_{\mathrm{c}}$ & crack length corresponding to $P_{\max }$ \\
\hline$B$ & specimen width \\
\hline$C M O D_{\mathrm{c}}$ & crack mouth opening displacement corresponding to $P_{\max }$ \\
\hline$D$ & specimen depth \\
\hline E & elastic modulus \\
\hline$f_{\mathrm{c}}$ & uniaxial compressive strength \\
\hline$f_{\mathrm{t}}$ & splitting tensile strength \\
\hline$G_{\mathrm{f}}$ & fracture energy \\
\hline K & stress intensity factor \\
\hline$K_{\mathrm{IC}}^{\mathrm{ini}}$ & initial fracture toughness \\
\hline$K_{\mathrm{IC}}^{\mathrm{un}}$ & unstable fracture toughness \\
\hline$m$ & empirical constant \\
\hline$n$ & empirical constant \\
\hline$P$ & load \\
\hline$P_{\text {ini }}$ & initial cracking load \\
\hline$P_{\text {ini, } 1}$ & load inducing the pressure stress \\
\hline$P_{\text {ini,2 }}$ & load contributing to the crack initiation \\
\hline$P_{\max }$ & peak load \\
\hline$P_{\max , 1}$ & load causing the unstable crack propagation \\
\hline$S$ & loading span for the specimen \\
\hline$t$ & loading duration \\
\hline$u$ & displacement component on the integral path in $\mathrm{x}$ direction \\
\hline$v$ & displacement component on the integral path in y direction \\
\hline$w$ & strain energy density \\
\hline$\varepsilon$ & strain \\
\hline$\&$ & strain rate \\
\hline$\Gamma$ & path for integration \\
\hline$\sigma$ & stress \\
\hline$\sigma_{\mathrm{xx}}$ & stress component in $\mathrm{x}$ direction \\
\hline$\sigma_{\mathrm{yy}}$ & stress component in y direction \\
\hline$\tau_{\mathrm{xy}}$ & stress component in xy direction \\
\hline
\end{tabular}




\section{Introduction}

Concrete gravity dams in service are usually subjected to long-term loading due to its function of storing water, where time-dependent creep behaviour exists in the concrete structures. Creep in concrete leads to stress redistributions, cracking and increased deformation, which may negatively affect the long-term serviceability and sustainability of the concrete dams. In contrast, when the water level drops, the concrete of gravity dams will enter the creep recovery stage and instantaneous recovery occurs after unloading [1,2]. The recovery of the creep deformation is only part of the initial creep deformation, while the rest part remains unrecoverable $[3,4]$. Together with the recovery of the creep deformation, the stress field in concrete will change in the recovery process. Considering the safety of the gravity dams in service, the effects of creep recovery on the crack resistance of concrete should be further explored so that the residual life of the dams can be comprehensively evaluated.

So far, the creep recovery behaviour of concrete has attracted much attention of academic and engineering communities. Creep behaviour of concrete can be classified as linear and nonlinear deformations depending on load levels. In general, linear viscoelastic behaviour of concrete occurs under low sustained loading. In contrast, under high sustained loading, the concrete exhibits nonlinear viscoelastic behaviour because of crack initiation, propagation and their interaction with the viscoelasticity of concrete [5,6]. For the creep recovery behaviour, the previous studies mainly focused on the effects of stress levels [6], concrete compositions including cement types [7], coarse aggregate [8], blast furnace slag [9] and polystyrene aggregate [10], and concrete strength [4] on the time-dependent behaviour. These investigations showed that the variations of the creep recovery deformation for concrete under compression and tension were similarly associated with the stress levels but hardly affected by the concrete compositions. Under high sustained loading, the recovery 
of creep deformation of the concrete consisted of crack closure and recovery creep deformation [3], while under low sustained loading, the linear viscoelastic characteristic of concrete would govern the recovery of creep deformation. The recovery of creep deformation was only part of the creep deformation and a large portion of the creep deformation was irretrievable. In addition, extensive investigations have been conducted to analyse the mechanisms of the creep recovery of concrete. The study by Davies [11] demonstrated that the variations of the creep and the recovery of the creep deformation were the same, where the increments of the creep and the recovery of the creep deformations were caused by the identical stresses with the opposite signs. For the unrecoverable creep deformation, Su et al. [2] and Rossi et al. [6] considered that it was caused by the accumulated micro-damage during the creep process. In contrast, Tang et al. [10] and Davies [11] stated that closure of voids in concrete, and viscous flow and swelling of the cement-paste occurring in the creep process were irreversible. Qian and Kawashima [12] stated that the viscoelastic fluid deformation of concrete occurring in the creep process caused unrecoverable creep deformation. Above-mentioned explanations did not show clear mechanism of creep recovery. Creep and stress relaxation are known to be interrelated in viscoelastic materials like concrete $[13,14]$, and the relationship between stress relaxation and creep can be characterised by an exact analytical expression. Stress relaxation in concrete leads to stress redistributions. In particular, for the pre-notched three-point bending (TPB) concrete beams subjected to long-term loading, the stress concentration existed at the tip of the pre-prepared notch $[15,16]$. The stress at the crack tip significantly decreased in the creep process due to the effect of stress relaxation. The stress relaxation occurring at the crack tip is local effect, while the creep deformation could be considered as structural effect. Similarly, during the creep recovery stage, the stress around the crack tip also influenced with the recovery of creep deformation [17]. However, the relation between the recovery 
of the creep deformation and the stress variation is not explicit. Therefore, to reasonably apprehend the creep recovery of concrete, it is necessary to quantitatively investigate and assess the variations of the stress and deformation of concrete during the creep recovery process.

Meanwhile, the fracture parameters, such as the initial fracture toughness $K_{\mathrm{IC}}^{\mathrm{ini}}$, the unstable fracture toughness $K_{\mathrm{IC}}^{\mathrm{un}}$ and the fracture energy $G_{\mathrm{f}}$, are generally considered as the material properties, which represent the fracture resistance and characteristics of concrete. Some investigations have been performed on the creep fracture properties of concrete [18-22]. Omar et al. [20] studied the variations of the creep fracture characteristics of concrete by conducting the TPB tests on the creep specimens, and the results indicated that the long-term loading almost had no effect on the residual capacity of creep specimens. However, according to the researches by Saliba et al. [21,22], $P_{\max }$ and $G_{\mathrm{f}}$ of concrete slightly increased after experiencing the creep process. This phenomenon was explained by the strengthening of the compressive zone of the TPB specimens in the creep process. In addition, Dong et al. [16] studied the creep fracture properties of concrete. According to the experimental and numerical results, they considered that the increments in $P_{\text {ini }}$ and $P_{\max }$ of concrete were caused by the stress relaxation at the crack tip during the creep process. Accordingly, when the effects of stress relaxations were considered, the calculated $K_{\mathrm{IC}}^{\mathrm{ini}}$ and $K_{\mathrm{IC}}^{\mathrm{un}}$ of the creep specimens were approximately equal to those under quasi-static conditions. In the case of creep recovery, the stress at the front of the crack tip would be accompanied by the recovery of the creep deformation [17,23], and affected the fracture behaviour of concrete. For assessing the cracking resistance of creep recovery concrete, it is necessary to perform further studies on the fracture characteristics of creep recovery concrete so that the fracture properties of concrete structures can be assessed accurately. Furthermore, the applicability of the fracture criteria with respect to $K_{\mathrm{IC}}^{\mathrm{ini}}$ and $K_{\mathrm{IC}}^{\mathrm{un}}$ under quasi-static conditions should be clearly clarified when they are used 
in the fracture analyses on concrete subjected to creep recovery.

To comprehensively understand the creep behaviour of concrete, many investigations have been conducted to analyse the time-dependent behaviour of concrete. Barpi and Valente [24,25] simulated the tertiary creep of concrete by employing the viscous rheological element to reveal the time-dependent behaviour in the fracture process zone (FPZ), and the obtained lifetime and load-displacement relationship from numerical analyses showed a good agreement with those from the experimental investigation. Zhou [26] also simulated the fracture process of concrete under sustained loading by introducing the Maxwell model to reflect the time-dependent behaviour in FPZ. Luzio [27] investigated the time-dependent fracture of concrete by employing the modified micro-plane model to characterise the viscoelasticity of the FPZ and un-cracked concrete. These studies presented successful modelling concepts for the tertiary creep of concrete under sustained loading. However, the investigations on the effects of creep recovery on the fracture behaviour of concrete are limited. Therefore, it is necessary to investigate the fracture properties of concrete after creep recovery and assess the effects of creep recovery on the fracture behaviour of concrete.

In line with this, the aim of this research is to study the creep recovery behaviour of concrete and its effects on the fracture characteristics of concrete. First, the TPB creep tests were carried out on the pre-notched concrete specimens at $60 \% P_{\max }$ over 30 days. Thereafter, the creep recovery tests were performed over different recovery durations. After the creep recovery tests, the specimens were subjected to quasi-static TPB loading until failure. The creep recovery deformation versus time curves, the initial cracking load and the peak load were obtained in the tests. In addition, by combining with the Norton-Bailey model, the time-dependent behaviour and the stress intensity factor (SIF) of the concrete subjected to the creep recovery were analysed numerically. Finally, the effects of creep recovery on the fracture parameters of concrete were assessed. 


\section{Experimental program}

154

155

156

157

158

\subsection{Specimen preparations}

The dimensions of the TPB specimens for the creep recovery tests were $500 \mathrm{~mm} \times 100 \mathrm{~mm} \times$ $100 \mathrm{~mm}$ with a $30 \mathrm{~mm}$ long pre-notch. The mix proportions of the concrete were cement : water : sand : aggregate $=1: 0.60: 2.01: 3.74$ by weight. The $42.5 \mathrm{~N}$ ordinary Portland cement [28], coarse aggregate with a maximum size of $10 \mathrm{~mm}$ and river sand with a maximum size of $5 \mathrm{~mm}$ were used for making the concrete. The specimens were demoulded one day after casting, and then kept in the curing chamber with $20 \pm 2^{\circ} \mathrm{C}$ and $90 \%$ relative humidity $(\mathrm{RH})$ for the next 27 days. After 28 days of casting, the pre-notch on each specimen was produced using a $2 \mathrm{~mm}$ thick diamond saw. The compressive strength $f_{\mathrm{c}}$, the splitting tensile strength $f_{\mathrm{t}}$ and the elastic modulus $E$ of concrete at the age of 28 days are listed in Table. 1. To further assess the effects of the 30-day loading duration in the creep tests, $f_{\mathrm{c}}, f_{\mathrm{t}}$ and $E$ were measured at the age of 58 days after the creep tests and the results are listed in Table 1. The mean values of $f_{\mathrm{c}}, f_{\mathrm{t}}$ and $E$ at both ages and their coefficients of variation $\left(C_{\mathrm{V}}\right)$ were also obtained and listed in the same table.

Table 1 Material properties of concrete at 28 and 58 days.

\begin{tabular}{ccccc}
\hline \multirow{2}{*}{ Material property } & & $\begin{array}{c}f_{\mathrm{c}} \\
(\mathrm{MPa})\end{array}$ & $\begin{array}{c}f_{\mathrm{t}} \\
(\mathrm{MPa})\end{array}$ & $\begin{array}{c}E \\
(\mathrm{GPa})\end{array}$ \\
\hline \multirow{3}{*}{28 days } & 1 & 39.94 & 2.83 & 32.7 \\
& 2 & 42.77 & 3.58 & 33.6 \\
& 3 & 34.67 & 2.79 & 34.1 \\
& Mean value & 39.10 & 3.07 & 33.5 \\
& $C_{\mathrm{V}}(\%)$ & 8.5 & 11.1 & 1.7 \\
\hline \multirow{3}{*}{58 days } & 1 & 43.01 & 3.04 & 34.2 \\
& 2 & 43.67 & 3.32 & 34.7 \\
& 3 & 38.74 & 3.26 & 35.2 \\
& Mean value & 41.81 & 3.21 & 34.7 \\
& $C_{\mathrm{V}}(\%)$ & 5.2 & 7.0 & 1.1 \\
\hline
\end{tabular}




\subsection{Creep recovery tests}

In order to accurately adjust the applied load in the sustained loading tests, the quasi-static TPB tests were carried out at the age of 28 days and the mean value of $P_{\max }$ for three specimens was obtained as $4.07 \mathrm{kN}$. The creep specimens were loaded using the loading frames as shown in Fig. 1 at $60 \% P_{\max }(60 \% \times 4.07 \approx 2.44 \mathrm{kN})$ over 30 days. The creep recovery tests were performed in a structural laboratory with $20 \pm 2{ }^{\circ} \mathrm{C}$ and $50 \% \mathrm{RH}$. In addition, aluminium tapes were used to wrap the specimens to prevent the loss of moisture in concrete so that only basic creep was investigated in this study. To ensure that the applied load to accurately reach the pre-set level, a steel bolt was connected onto a load sensor and a digital display was used to monitor the variations of the applied load. Once the applied load dropped by $2 \%$ due to the increase of creep deformation, the load would be increased to the pre-set level. After the creep tests, the sustained load would be removed and the recovery tests were carried out after 1, 2, 3 and 15 days, respectively. The dial indicators were employed to detect the loading point displacement $(\delta)$. Besides, two specimens named as the "aging specimens" were made at one time and stored under the same curing conditions as those specimens subjected to creep recovery but without loading.

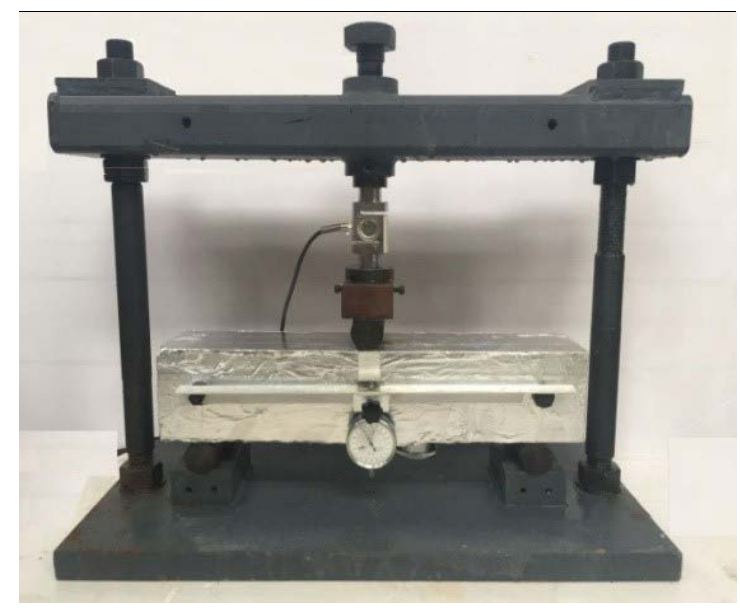

Fig. 1. Set-up for the creep tests.

\subsection{Quasi-static TPB tests}

After the creep recovery tests, the specimens were moved out from the loading frames and sustained quasi-static TPB tests immediately. A $250 \mathrm{kN}$ closed loop servo-controlled MTS testing machine was employed for the quasi-static TPB tests with a displacement rate of $0.036 \mathrm{~mm} / \mathrm{min}$. To 
accurately detect the load values in the test, a load cell with a capacity of $50 \mathrm{kN}$ was used. Since the $P_{\max }$ for different series specimens was about $4000 \mathrm{~N}$, it took about 10 minutes to load to $P_{\max }$ at this loading rate. The creep specimens after 30-day sustained loading and the aging specimens were also tested under quasi-static loading. To detect the crack initiation, four $10 \mathrm{~mm} \times 2 \mathrm{~mm}$ (length $\times$ width) strain gauges were symmetrically mounted on both sides of concrete beams at a horizontal distance of $5 \mathrm{~mm}$ to the pre-notch tip, as shown in Fig. 2. The values of the strain gauges would increase under the quasi-static TPB loading with the increase of the load. When a new crack initiated at the tip of the pre-notch, the values of the strain gauges would decrease due to the release of the strain energy stored around the crack tip [29-31]. Fig. 2(b) shows that with the increase of the applied load, the strain value $\varepsilon$ increased from zero to the maximum value $\varepsilon_{\text {max }}$, Thereafter, the strain gradually decreased due to the crack initiation. Accordingly, the load corresponding to $\varepsilon_{\max }$ could be regarded as the initial cracking load. In addition, two clip gauges were employed to detect the variations of $\delta$ and the crack mouth opening displacement (CMOD), as shown in Fig. 3.

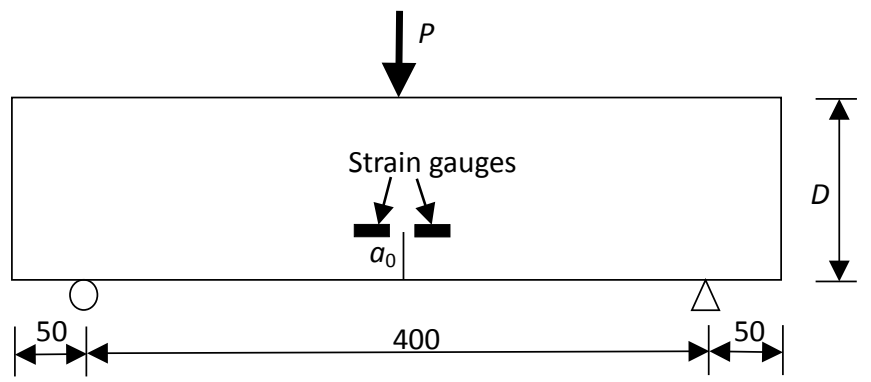

(a) Locations of the strain gauges

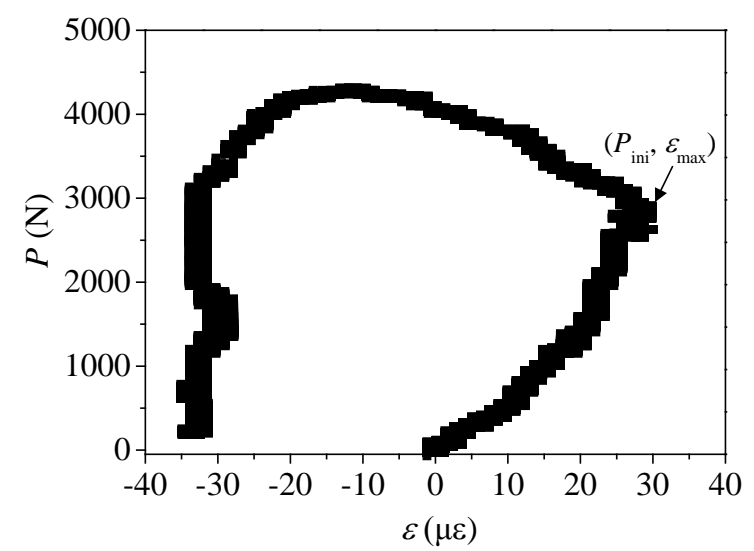

(b) Load - strain curve with $P_{\text {ini }}$ and $\varepsilon_{\max }$

Fig. 2. Arrangement of strain gauges on a specimen surface and strain variations with loading. 


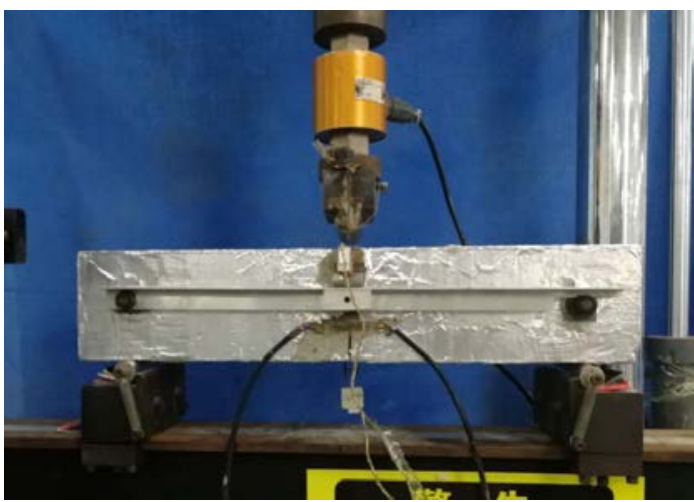

Fig. 3. Set-up for the quasi-static TPB tests.

\section{Numerical analyses}

To investigate the creep recovery behaviour of concrete, a nonlinear creep model called the

Norton-Bailey model was introduced to reflect the relationship of creep with stress and loading time in concrete as follows [32]

$$
\varepsilon=A \cdot \sigma_{\mathrm{t}}^{\mathrm{n}} \cdot t^{\mathrm{m}}
$$

where $\varepsilon$ is the strain, $A, n$ and $m$ are empirical constants, and $\sigma_{\mathrm{t}}$ is the stress at the crack tip for a loading duration $t$.

By differentiating Eq. (1) with respect to $t$, the creep strain rate can be obtained as

$$
\&=A \cdot m \cdot \sigma_{\mathrm{t}}^{\mathrm{n}} \cdot t^{\mathrm{m}-1}
$$

and the time versus stress relationship can be expressed as [33]

$$
t=\frac{1}{A \cdot E \cdot(n-1)}\left(\frac{1}{\sigma_{\mathrm{t}}^{\mathrm{n}-1}}-\frac{1}{\sigma_{0}^{\mathrm{n}-1}}\right)
$$

where $\sigma_{0}$ is the initial stress under the sustained load $P_{0}$ at the time $t=0$. After the creep develops over a time duration $\left(t_{1}-t_{0}\right)$, the sustained load $P_{0}$ on the specimen was removed and the recovery test was performed over a time duration $\left(t_{2}-t_{1}\right)$. This is equivalent to applying an opposite load of $-P_{0}$ on the creep specimen from $t_{1}$ to $t_{2}$. The loading history can be shown in Fig. 4, including the creep stage from $t_{0}$ to $t_{1}$ and the creep recovery stage from $t_{1}$ to $t_{2}$. Correspondingly, the strain rate during the creep recovery process can be expressed as

$$
\&=\sum_{\mathrm{t}_{0}}^{\mathrm{t}_{1}} A \cdot m \cdot \sigma_{\mathrm{t}}^{\mathrm{n}} \cdot t^{\mathrm{m}-1}-\sum_{\mathrm{t}_{1}}^{\mathrm{t}_{2}} A \cdot m \cdot \sigma_{\mathrm{t}}^{\mathrm{n}} \cdot t^{\mathrm{m}-1}
$$


Fig. 4. Creep recovery process. and $m$ during the recovery stage were determined as $2.6 \times 10^{-4}, 4.0$ and 0.28 , respectively. 


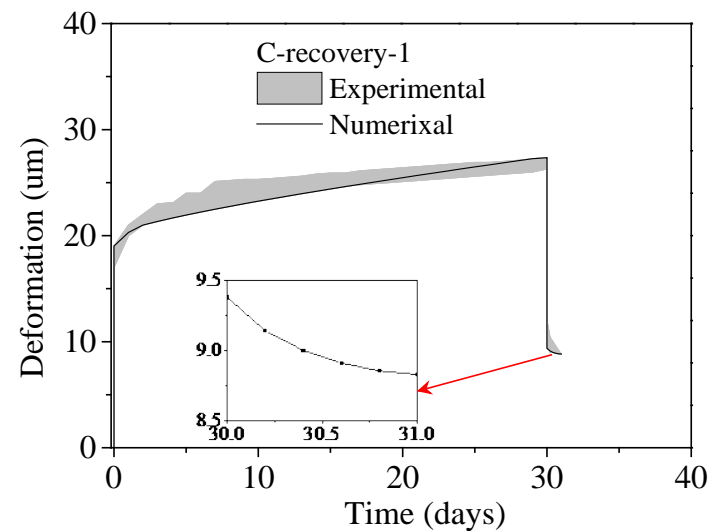

(a) Specimen C-recovery-1

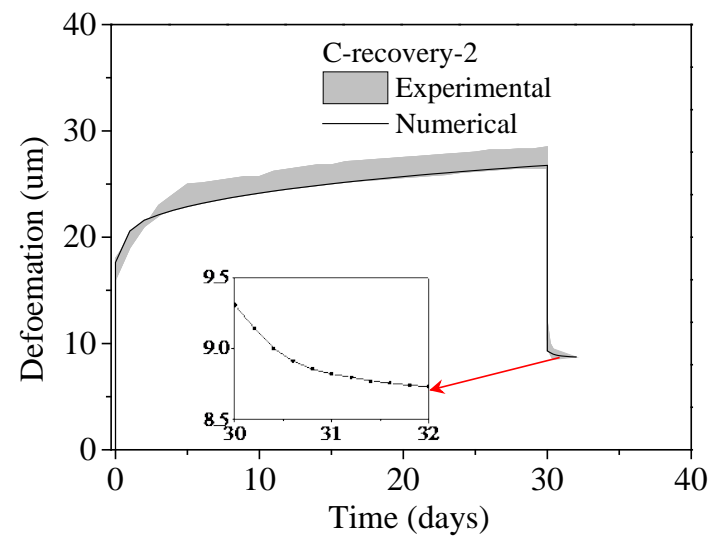

(b) Specimen C-recovery-2

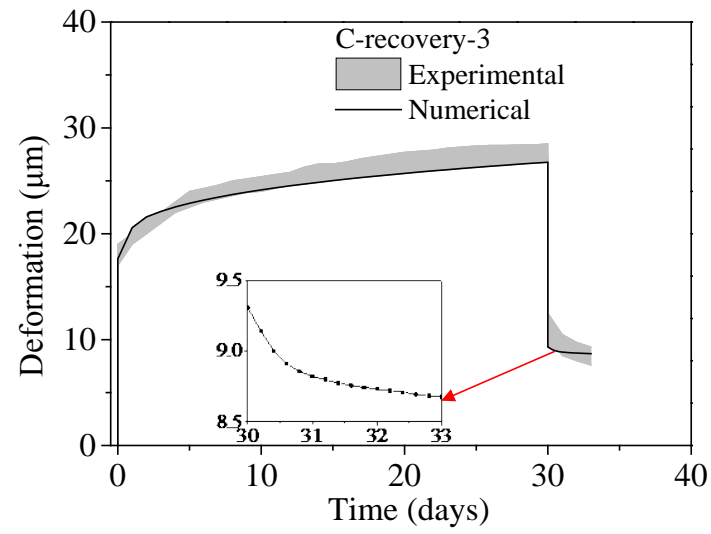

(c) Specimen C-recovery-3 


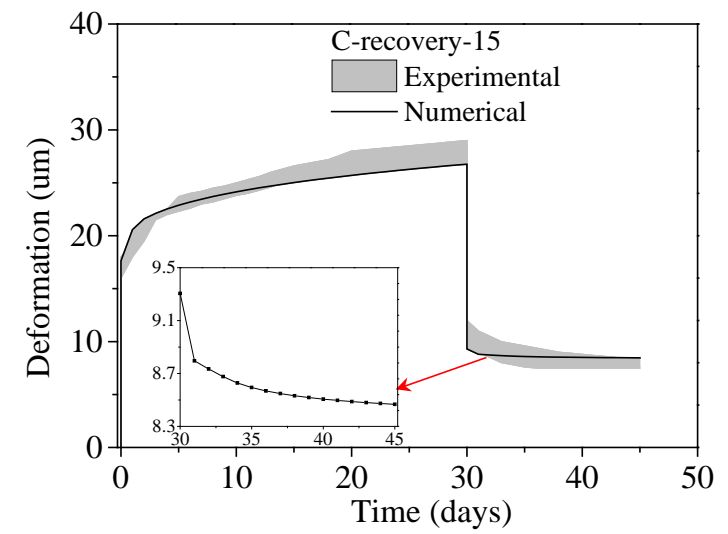

(d) Specimen C-recovery-15

Fig. 5. Loading point deformation versus time curves for different recovery ages.

Meanwhile, by combining with the Norton-Bailey model, the finite element software ANSYS 14.5 was employed to analyse the time-dependent behaviour of concrete during the creep and creep recovery stages. Plane 182 elements provided by ANSYS 14.5 were used in the numerical simulations, which are 2-D 3-node elements with quadratic displacement features. These elements also support the analyses on the creep behaviour of different materials. To define the variations of material properties of concrete during the 30-day creep process, the material properties were also obtained at the age of 58 days. The test results in Table 1 indicate that the materials properties of concrete slightly increased when the age changed from 28 days to 58 days. Considering the material properties of concrete did not significantly change in the creep process, the material parameters at 28 days were adopted in the numerical analyses. The triangle element mesh was used in the numerical simulations. Due to the stress singularity at the crack tip, a singular circle with a radius of $2 \mathrm{~mm}$ was utilised at the crack tip. The meshes of the beam and the circle at crack tip are shown in Fig. 6.
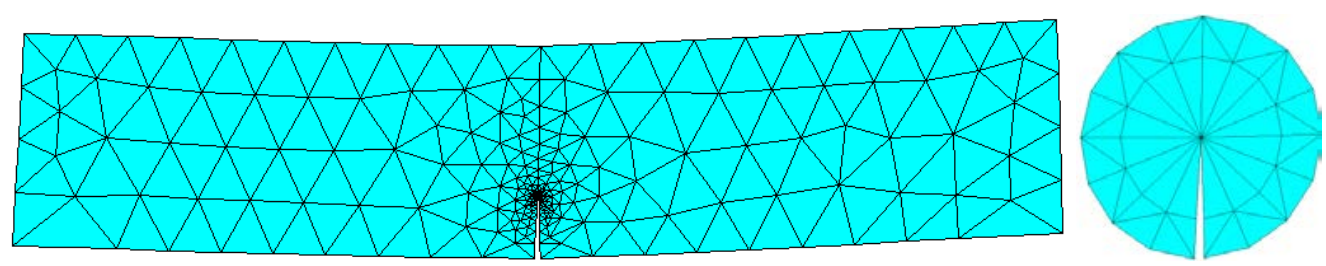

Fig. 6. Element meshes of the beam model

In addition, the $J$-integral method was used to analyse the variations of the stress intensity factor, where $J$-integral can be obtained with the formulas below [37] 


$$
J=\int_{\Gamma}\left[\left(w-\sigma_{\mathrm{xx}} \frac{\partial u}{\partial x}-\tau_{\mathrm{xy}} \frac{\partial v}{\partial x}\right) d y+\left(\tau_{\mathrm{xy}} \frac{\partial u}{\partial x}+\sigma_{\mathrm{yy}} \frac{\partial v}{\partial x}\right) d x\right]
$$

where $w$ is the strain energy density, $\sigma_{\mathrm{xx}}, \sigma_{\mathrm{yy}}$ and $\tau_{\mathrm{xy}}$ are the stress components, $u$ and $v$ are the strain components on the path for the integration, and $\Gamma$ is the integral path. After obtaining the $J$-integral value, the SIF $K$ can be calculated by using the following fomulae

$$
J=\frac{K^{2}}{E}
$$

where $E$ is the elastic modulus. In this study, the mean values of six integral paths around the crack tip within a 2-mm radius were used to calculate the SIF $K$. Since the stress concentration mainly occurred at the crack tip, the $J$-integral was performed within the $2 \mathrm{~mm}$ region at the crack tip. Accordingly, six integral paths with the distance of $0.06 \mathrm{~mm}, 0.12 \mathrm{~mm}, 0.23 \mathrm{~mm}, 0.43 \mathrm{~mm}, 0.77$ $\mathrm{mm}$ and $1.47 \mathrm{~mm}$ to the crack tip were selected for the $J$ integral calculations. In the numerical analyses, the proposed model can automatically take into account the variations of the stress and displacement fields with time. Accordingly, the SIF obtained from $J$-integral could also automatically reflect the variations of stress in the creep recovery process.

\section{Results and discussion}

\subsection{Effects of creep recovery on the stress variations at the crack tip}

The variations of the stress at the nodes within the $2 \mathrm{~mm}$ region around the crack tip were obtained numerically and are shown in Fig. 7. Here, the mean value of the stresses at these nodes is taken as as the nominal stress, and its variations during the creep and creep recovery stages are illustrated in Fig.8. At the creep stage, the stresses in front of the crack tip were in tension, which decreased rapidly at first and then gradually stabilised according to Eq. (4). The nominal stress decreased from 28.1 MPa (Point A in Fig. 8) to 11.8 MPa (Point B in Fig. 8) over 30 days. Once the creep tests were finished at the end of the 30th day, the applied sustained load of $60 \% P_{\max }$ was removed and then the recovery tests were carried out, which is equivalent to applying an opposite load $-60 \% P_{\max }$ on the creep specimens. At that moment, the pressure stress caused by this $-60 \% P_{\max }$ were generated at the crack tip, with the nominal stress of $-16.3 \mathrm{MPa}$. The variation of the nominal 
stress caused by this $-60 \% P_{\max }$ was $11.8+16.3=28.1 \mathrm{MPa}$, which was equal to the stress caused by the sustained load of $60 \% P_{\max }$ at the initial creep stage. During the creep recovery stage, the relationship between stress, strain and time can be expressed by using Eq. (1). The nominal stress in concrete gradually decreased due to the effect of stress relaxation as well as the recovery of creep deformation. The values of the nominal stress were obtained as 14.6 MPa, 13.3 MPa, 12.2 MPa and 8.8 MPa for the recovery times of 1, 2, 3 and 15 days, see Points C, D, E and F in Fig. 8.

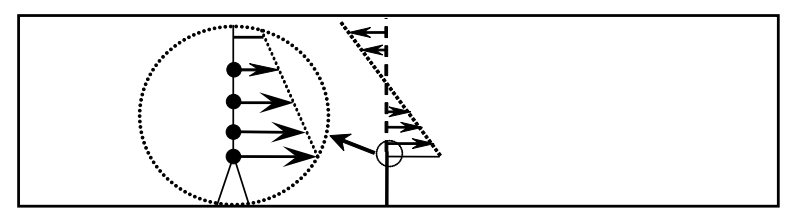

Fig. 7. Stress distributions in front of the pre-crack tip.

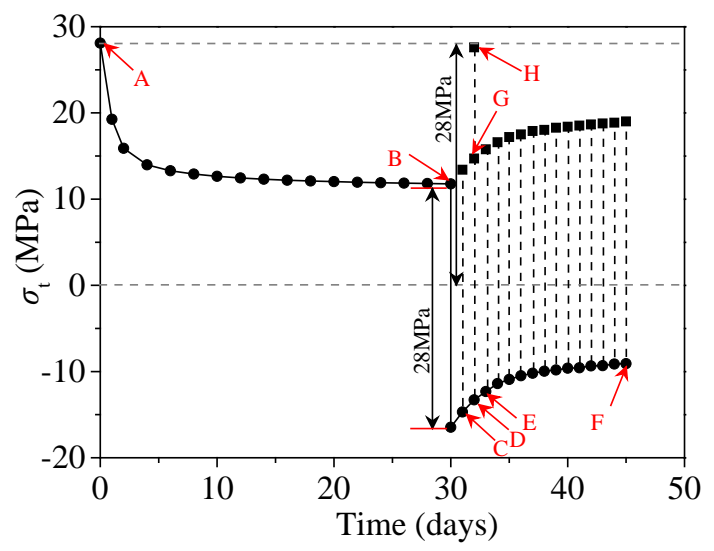

Fig. 8. Variations of the stress in the creep recovery process.

After the creep recovery tests, when the applied load reached $60 \% P_{\max }$ under quasi-static TPB loading, the total nominal tensile stress caused by this $60 \% P_{\max }$ would be $28.1 \mathrm{MPa}$. However, since there existed the nominal pressure stress around the crack tip at the end of the creep recovery stage, the actual nominal stress corresponding to the quasi-static TPB load of $60 \% P_{\max }$ should be the sum of this $28.1 \mathrm{MPa}$ and the pressure nominal stress at the end of the creep recovery stage. Taking Specimen C-recovery-2 as an example, the nominal stress corresponding to the quasi-static TPB load of $60 \% P_{\max }$ (Point G in Fig. 8) should be $28.1-10.5=17.6 \mathrm{MPa}$. Therefore, by comparing with the nominal stress under the same load of $60 \% P_{\max }$ at the start of the creep stage, i.e. 28.1 MPa (Point A in Fig.8), the nominal stress decreased obviously due to the effect of stress relaxation during the creep and creep recovery stages. Accordingly, a load increment should be 
provided to make the nominal stress at the crack tip recover to 28.1 MPa at Point $\mathrm{H}$ in Fig. 8.

In summary, accompanied by the increment of creep deformation, the stress at the crack tip would decrease due to stress relaxation at the creep stage. When the load was removed, the concrete would enter the creep recovery stage. At that moment, the elastic creep deformation would begin to recovery. Meanwhile, the unrecovered creep deformation and residual stress would also exist in the concrete. The relationship between stress, strain and time can be still characterized by the analytical expression Eq. (1). Accordingly, accompanied by the recovery of the creep deformation, the stress relaxation at the crack tip would also occur over the time. Thereafter, in the following quasi-static tests, a load increment would be used to cover the residual stress in concrete, which would affect the fracture properties of concrete.

\subsection{Effects of creep recovery on the fracture characteristics of concrete}

Once the creep recovery tests were finished, the quasi-static TPB tests were carried out on the specimens. The load versus crack mouth opening displacement $(P-C M O D)$ curves were obtained and are shown in Fig.9. According to the experimental results, the initial cracking load $P_{\text {ini, }}$, the peak load $P_{\max }$, the initial fracture toughness $K_{\mathrm{IC}}^{\mathrm{ini}}$, the unstable fracture toughness $K_{\mathrm{IC}}^{\mathrm{un}}$ and the fracture energy $G_{\mathrm{f}}$ were obtained and listed in Table 2, where C-aging and C-creep represent the aging and creep specimens, respectively. It can be seen that the creep recovery process had no influence on the fracture energy. The fracture energies of the creep and creep recovery concrete specimens would be related to the accumulated damage. In this study, due to short creep time and low load level, no great damage occurred during the creep and creep recovery processes. Meanwhile, comparing with the aging specimens, the fracture energies from the creep and creep recovery specimens did not change significantly. However, the average values of $P_{\text {ini }}$ for the C-creep and C-recovery series specimens increased obviously compared with those of the C-aging series specimens, as shown in Fig. 10. In addition, comparing with the C-creep series specimens, the average values of $P_{\text {ini }}$ for the specimens subjected to creep recovery decreased during the recovery stage. The mean values of $P_{\text {ini }}$ for the C-recovery-1, C-recovery-2, C-recovery-3 and C-recovery-15 series specimens decreased by 


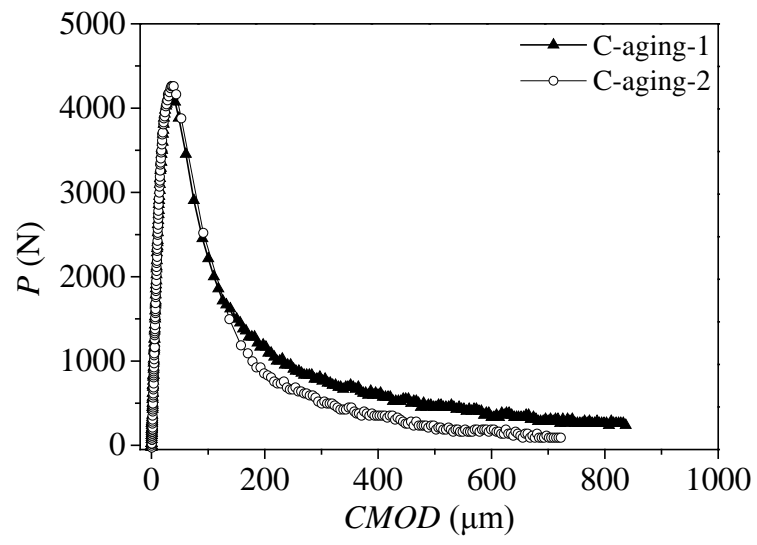

(a) C-aging series specimens

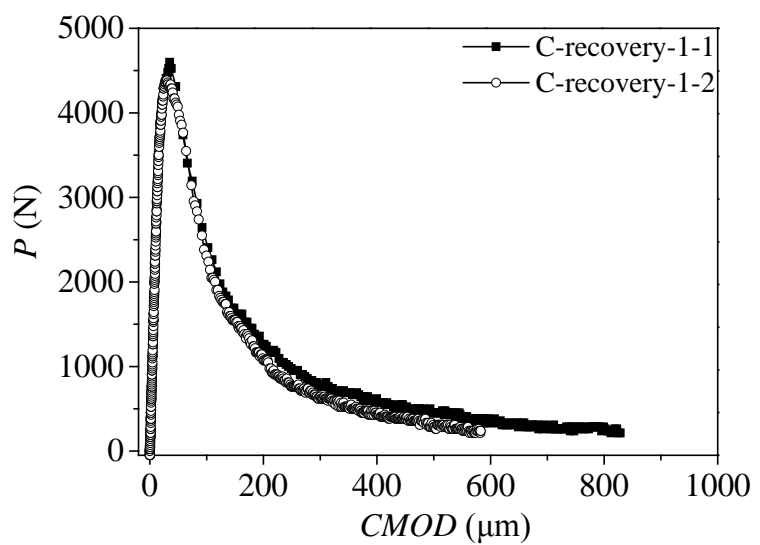

(c) C-recovery-1 series specimens

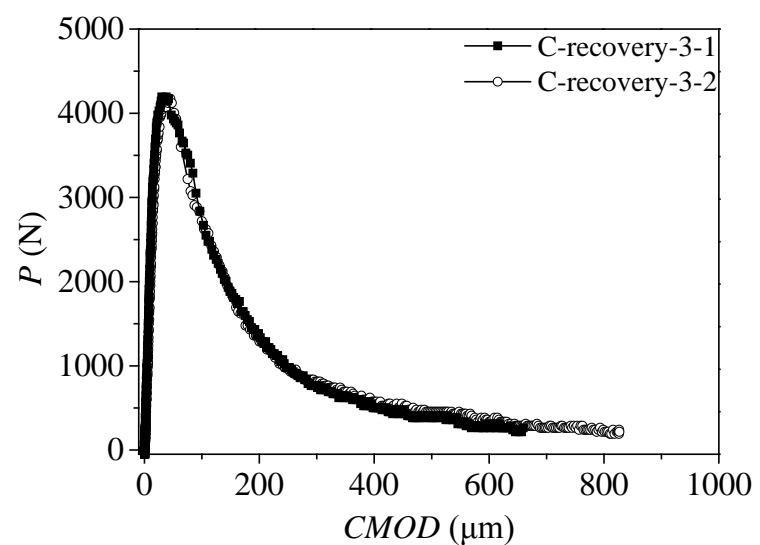

352

(e) C-recovery-3 series specimens

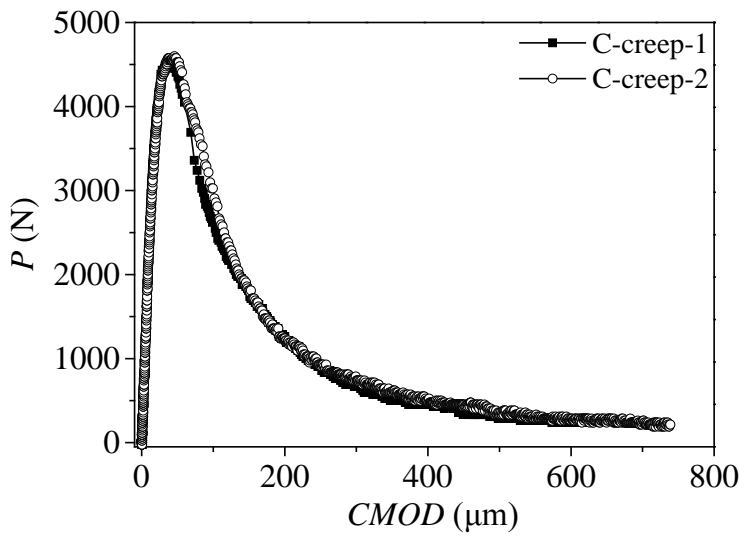

(b) C-aging series specimens

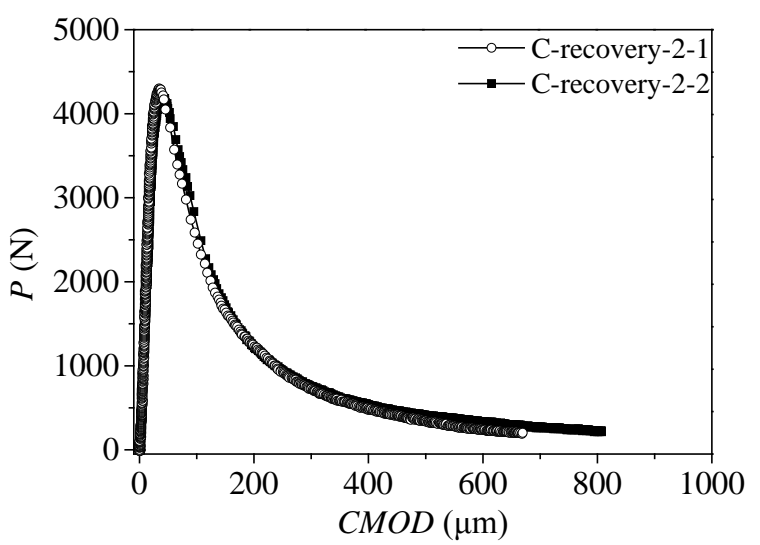

(d) C-recovery-2 series specimens

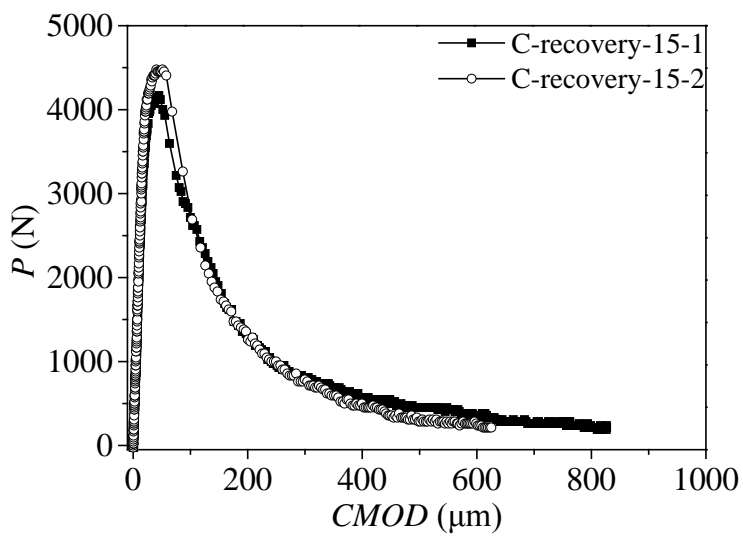

(f) C-recovery-15 series specimens

Fig. 9. P-CMOD curves for different series specimens 
Table 2 Experimental results for different series specimens.

\begin{tabular}{|c|c|c|c|c|c|c|c|c|c|c|}
\hline \multirow{2}{*}{ Specimens } & \multirow{2}{*}{$\begin{array}{l}P_{\text {ini }} \\
(\mathrm{N})\end{array}$} & \multirow{2}{*}{$\begin{array}{l}P_{\text {ini, } 1} \\
(\mathrm{~N})\end{array}$} & \multirow{2}{*}{$\begin{array}{l}P_{\mathrm{ini}, 2} \\
(\mathrm{~N})\end{array}$} & \multirow{2}{*}{$\begin{array}{c}P_{\max } \\
(\mathrm{N})\end{array}$} & \multicolumn{2}{|c|}{$K_{\mathrm{IC}}^{\mathrm{ini}}\left(\mathrm{MPa} \cdot \mathrm{m}^{0.5}\right)$} & \multirow{2}{*}{$\begin{array}{c}K_{\mathrm{IC}}^{\mathrm{un}} \\
\left(\mathrm{MPa} \cdot \mathrm{m}^{0.5}\right)\end{array}$} & \multirow{2}{*}{$\begin{array}{c}C M O D_{\mathrm{C}} \\
(\mu \mathrm{m})\end{array}$} & \multirow{2}{*}{$\begin{array}{c}a_{\mathrm{c}} \\
(\mathrm{mm})\end{array}$} & \multirow{2}{*}{$\begin{array}{c}G_{\mathrm{f}} \\
(\mathrm{N} / \mathrm{m})\end{array}$} \\
\hline & & & & & Numerical & Eq. (8) & & & & \\
\hline C-aging-1 & 2905 & & & 4308 & 0.52 & 0.55 & 1.35 & 36.7 & 17.8 & 115.89 \\
\hline C-aging-2 & 3174 & I & 1 & 4216 & 0.57 & 0.61 & 1.27 & 33.9 & 16.6 & 135.77 \\
\hline Mean & 3039 & & & 4262 & 0.54 & 0.58 & 1.31 & 35.3 & 17.2 & 125.83 \\
\hline C-creep-1 & 3502 & & 3072 & 4550 & 0.58 & 0.59 & 1.33 & 37.5 & 18.6 & 119.01 \\
\hline C-creep-2 & 3240 & 430 & 2774 & 4598 & 0.51 & 0.53 & 1.28 & 34.6 & 17.1 & 130.76 \\
\hline Mean & 3367 & & 2937 & 4574 & 0.54 & 0.56 & 1.30 & 36.1 & 17.8 & 123.47 \\
\hline C-recovery-1-1 & 3397 & & 3047 & 4585 & 0.58 & 0.58 & 1.31 & 35.3 & 17.3 & 120.89 \\
\hline C-recovery-1-2 & 3310 & 350 & 2960 & 4407 & 0.55 & 0.56 & 1.25 & 33.3 & 17.1 & 129.25 \\
\hline Mean & 3353 & & 3003 & 4496 & 0.56 & 0.57 & 1.28 & 34.3 & 17.2 & 125.07 \\
\hline C-recovery-2-1 & 3240 & & 2920 & 4193 & 0.55 & 0.56 & 1.25 & 35.8 & 18.6 & 127.21 \\
\hline C-recovery-2-2 & 3299 & 320 & 2979 & 4305 & 0.57 & 0.57 & 1.25 & 34.4 & 17.6 & 112.89 \\
\hline Mean & 3269 & & 2949 & 4249 & 0.55 & 0.56 & 1.25 & 35.1 & 18.1 & 120.05 \\
\hline C-recovery-3-1 & 3390 & & 3090 & 4271 & 0.60 & 0.59 & 1.32 & 37.5 & 19.5 & 125.79 \\
\hline C-recovery-3-2 & 3116 & 300 & 2816 & 4264 & 0.52 & 0.54 & 1.23 & 34.1 & 17.4 & 122.46 \\
\hline Mean & 3253 & & 2953 & 4267 & 0.56 & 0.56 & 1.27 & 35.8 & 18.5 & 124.12 \\
\hline C-recovery-15-1 & 3254 & & 2994 & 4169 & 0.59 & 0.57 & 1.32 & 38.1 & 20.2 & 137.14 \\
\hline C-recovery-15-2 & 3151 & 260 & 2891 & 4455 & 0.54 & 0.55 & 1.27 & 34.1 & 16.6 & 124.63 \\
\hline Mean & 3202 & & 2942 & 4312 & 0.57 & 0.56 & 1.30 & 36.2 & 18.4 & 130.88 \\
\hline
\end{tabular}

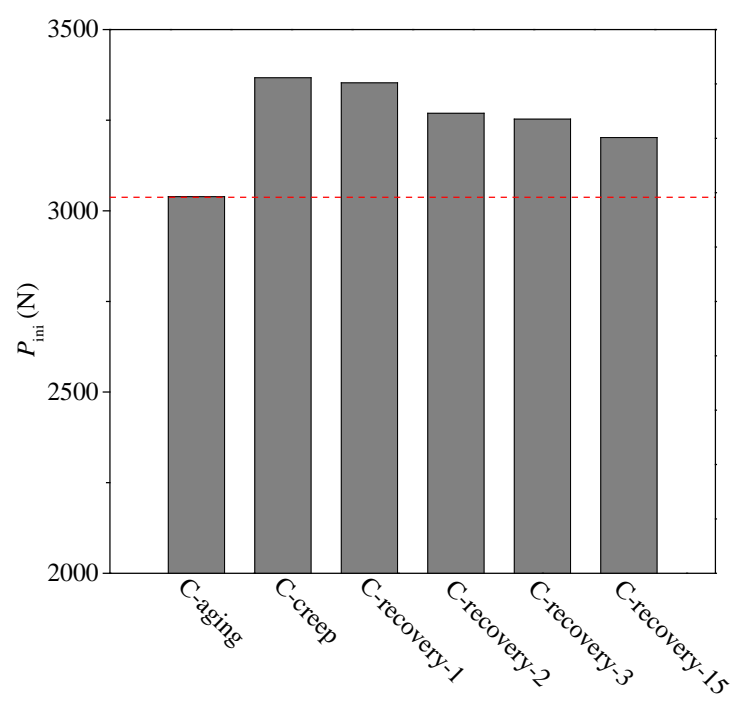

Fig. 10. $P_{\text {ini }}$ for different series specimens.

To study the effects of creep and creep recovery on the crack resistance of concrete, the

359 evolutions of the SIF in the whole loading process were numerically determined (see Fig. 11). 
the most importance factor influencing the fracture behaviour of concrete. It can be seen that the creep tests were conducted under the sustained load $P_{0}$ over a time duration from $t_{0}$ to $t_{1}$. Due to the effect of stress relaxation in concrete, the SIF would decrease from $K_{0}$ (Point A in Fig. 11) at the time of $t_{0}$ to $K_{1}$ (Point B in Fig. 11) at the time of $t_{1}$. Thereafter, the sustained load was removed, and the recovery tests would be conducted over a time duration from $t_{1}$ to $t_{2}$. In the recovery stage, the pressure stress generated at the crack tip would also relax over the time. However, the SIF would be zero because it could not be negative. After the recovery tests, the quasi-static TPB tests were performed on the specimens. In these tests, when the load increased to $P_{0}$, i.e. the sustained load in the creep process, the corresponding SIF sustained a decrement of $\Delta K_{0}$ from $K_{0}$ (Point $C$ in Fig. 11) due to the stress relaxation in the creep and creep recovery processes. Accordingly, when the SIF reached $K_{0}$ (Point D in Fig. 11) in the quasi-static tests, the corresponding load should gain an increment of $P_{\text {ini, } 1}$ from the sustained load $P_{0}$, which induced the decrement of $\Delta K_{0}$. Furthermore, the crack would initiate when the load increased to $P_{\text {ini, }}$ and $K_{\mathrm{IC}}^{\mathrm{ini}}$ could be obtained accordingly (Point E in Fig. 11). Fig. 11 illustrates the variations of the SIF at different processes. It can be seen that in the quasi-static TPB tests, a load increment $\left(P_{\text {ini, } 1}\right.$ in Fig. 11$)$ would be used to cover the decrement of the SIF in the creep and creep recovery processes, and this caused the increment of initial cracking load. Accordingly, the initial cracking loads for the creep and creep recovery concrete were composed of two parts: one part was the initial cracking load which was used to cover the decrement of the SIF in the creep and creep recovery process, while the other part caused the elastic deformation and contributed to the crack initiation. Thus, Fig. 11 illustrates that considering the effects of stress relaxation occurring in the creep and creep recovery processes, the initial fracture toughnesses of the creep and creep recovery concrete specimens would be equal to those of the concrete specimens under quasi-static conditions. Taking Specimen C-recovery-1-1 as an example, the calculated SIFs, $K_{0}$ and $K_{1}$, under $P_{0}=2.44 \mathrm{kN}$ during the creep stage were 0.42 $\mathrm{MPa} \cdot \mathrm{m}^{0.5}$ and $0.32 \mathrm{MPa} \cdot \mathrm{m}^{0.5}$, respectively. In the quasi-static TPB tests, the SIF reached 0.42 $\mathrm{MPa} \cdot \mathrm{m}^{0.5}$ under the load of $2.75 \mathrm{kN}$ with $P_{\text {ini, } 1}=0.35 \mathrm{kN}$. When the load increased to $3.35 \mathrm{kN}$, the 
crack would initiate with $K_{\mathrm{IC}}^{\mathrm{ini}}=0.57 \mathrm{MPa} \cdot \mathrm{m}^{0.5}$.

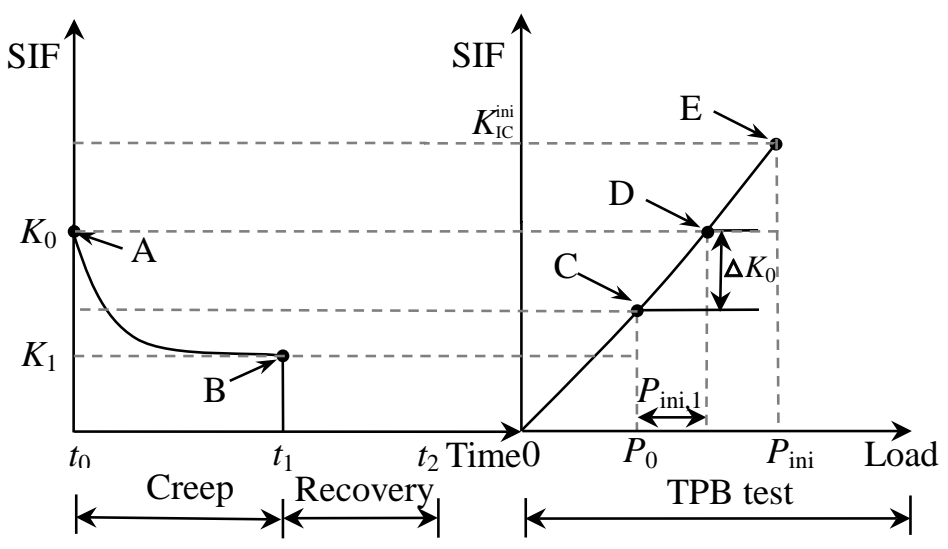

Fig. 11. Variations of the SIFs in the creep process and TPB tests.

According to the numerical results, the mean values of the initial fracture toughness for the C-aging, C-creep, C-recovery-1, C-recovery-2, C-recovery-3 and C-recovery-15 series specimens were $0.54 \mathrm{MPa} \cdot \mathrm{m}^{0.5}, 0.54 \mathrm{MPa} \cdot \mathrm{m}^{0.5}, 0.56 \mathrm{MPa} \cdot \mathrm{m}^{0.5}, 0.55 \mathrm{MPa} \cdot \mathrm{m}^{0.5}, 0.56 \mathrm{MPa} \cdot \mathrm{m}^{0.5}$ and 0.57 $\mathrm{MPa} \cdot \mathrm{m}^{0.5}$, respectively. Correspondingly, the mean values of the initial cracking load for these series specimens were 3.04 kN, 3.37 kN, 3.35 kN, 3.27 kN, 3.25 kN and $3.20 \mathrm{kN}$, respectively.

In addition, the values of $P_{\text {ini,1 }}$ obtained from the numerical analyses were $430 \mathrm{~N}, 350 \mathrm{~N}, 320 \mathrm{~N}$, $300 \mathrm{~N}$ and $260 \mathrm{~N}$ for the C-creep, C-recovery-1, C-recovery-2, C-recovery-3 and C-recovery-15 specimens, respectively (see Table 2). Meanwhile, $P_{\text {ini,1 }}$ decreased with the increase of the recovery time because the stress relaxation would increase over the recovery time. Therefore, for the C-creep and C-recovery series specimens, $P_{\text {ini }}$ was composed of two parts, i.e. $P_{\text {ini, } 1}$ and $P_{\text {ini,2, }}$, as indicated below

$$
P_{\text {ini }}=P_{\text {ini, } 1}+P_{\text {ini,2 }}
$$

where $P_{\text {ini,1 }}$ was considered to induce the pressure stress at the end of the creep recovery stage and $P_{\text {ini,2 }}$ contributed to the crack initiation.

The initial fracture toughness $K_{\mathrm{IC}}^{\mathrm{ini}}$ for the creep and creep recovery specimens can be calculated based on the LEFM as follows [38]

$$
K=\frac{3 P S}{B D^{2}} \sqrt{a_{0}} F(\alpha)
$$


412 with

$$
F\left(\frac{a_{0}}{D}\right)=\frac{1.99-\frac{a_{0}}{D}\left(1-\frac{a_{0}}{D}\right)\left[2.15-3.93 \frac{a_{0}}{D}+2.7\left(\frac{a_{0}}{D}\right)^{2}\right]}{\left(1+2 \frac{a_{0}}{D}\right)\left(1-\frac{a_{0}}{D}\right)^{3 / 2}}
$$

where $B$ is the specimen width, $D$ is the specimen depth, $S$ is the loading span for the specimen, and $a_{0}$ is the pre-notch depth.

The calculated results are listed in Table 2, which indicates that the initial fracture toughnesses obtained from Eq. (8) for the creep and creep recovery specimens had good agreements with those from the numerical simulations. In addition, when the effects of stress relaxation were considered, the initial fracture toughnesses of the specimens subjected to the creep and creep recovery stages obtained from Eq. (8) were approximately equal to those of the aging specimens.

Considering that the stress relaxations during the creep and recovery stages were induced by $P_{\text {ini,1, }}$, the load difference $\left(P_{\max }-P_{\text {ini, } 1}\right)$ contributed to the unstable crack propagation based on the LEFM theory. Thus, $P_{\max }$ of the concrete subjected to the creep and creep recovery stages can be expressed as

$$
P_{\max }=P_{\text {ini, } 1}+P_{\max , 1}
$$

where $P_{\text {max, } 1}$ was considered to cause the unstable crack propagation in the quasi-static tests.

In addition, the critical crack length $a_{\mathrm{c}}$, i.e. the crack length related to $P_{\max }$, is an important parameter for evaluating instability of concrete. The previous experimental investigations [16] have confirmed that the creep had little effect on the critical crack length of concrete. Based on the LEFM theory [30], $a_{\mathrm{c}}$ can be obtained from Eq. (11) as

$$
C M O D_{\mathrm{c}}=\frac{24 P_{\max } a_{\mathrm{c}}}{B D E} V\left(\frac{a_{\mathrm{c}}}{D}\right)
$$

431 For $S / D=4, V\left(\frac{a_{c}}{D}\right)$ can be expressed as follow

$$
V\left(\frac{a_{\mathrm{c}}}{D}\right)=0.76-2.28\left(\frac{a_{\mathrm{c}}}{D}\right)+3.87\left(\frac{a_{\mathrm{c}}}{D}\right)^{2}-2.04\left(\frac{a_{\mathrm{c}}}{D}\right)^{3}+0.66\left(1-\frac{a_{\mathrm{c}}}{D}\right)^{-2}
$$


where $C M O D_{\mathrm{c}}$ is the crack mouth opening displacement corresponding to $P_{\max }$. The values of $C M O D_{\mathrm{c}}$ for the $\mathrm{C}$-aging, C-creep and C-recovery series specimens were determined experimentally and are listed in Table 2. The values of $C M O D_{\text {c }}$ for different series specimens were similar. The increment load $P_{\text {ini,1 }}$ seemed to have no significant effects on the deformation under the later quasi-static tests. According to the previous discussion, the load $P_{\text {ini, } 1}$ was considered to induce the stress relaxation and the load $P_{\max , 1}$ actually contributed to the unstable crack propagation. Therefore, it was also considered that $C M O D_{\text {c }}$ was caused by the load $P_{\max , 1}$. By substituting $P_{\max , 1}$ into Eq. (11), the values of $a_{\mathrm{c}}$ for the creep and creep recovery specimens can be obtained and are listed in Table 2. The values of $a_{\mathrm{c}}$ from Eq. (11) for different series specimens were similar. The same findings for the creep specimens have also been given in literature [16].

Once obtaining the critical crack length $a_{\mathrm{c}}, K_{\mathrm{IC}}^{\mathrm{un}}$ can be calculated based on Eq. (8) by replacing $P_{\text {ini, } 2}$ and $a_{0}$ with $P_{\max , 1}$ and $a_{\mathrm{c}}$. The calculated results in Table 2 indicate no significant effects of creep and creep recovery on the unstable fracture toughness. Meanwhile, the experimentally obtained values of $K_{\mathrm{IC}}^{\mathrm{un}}$ from Eq. (8) showed good agreements with those from the numerical simulations. Accordingly, if the stress relaxation was considered, the LEFM theory could be used to calculate the fracture parameters of the creep and creep recovery concrete. In addition, the initial and unstable fracture toughnesses in the quasi-static tests can still be considered as the material parameters to assess the crack initiation and instability of concrete during the creep recovery stage.

\section{Conclusions}

To investigate the influence of creep recovery on the fracture characteristics of concrete, the TPB specimens were subjected to $60 \% P_{\max }$ over 30 days. Afterwards, the applied loads were removed and the recovery tests were performed after 1, 2, 3 and 15 days, respectively. Thereafter, the quasi-static TPB tests were performed on the creep recovery specimens. The variations of the stress at the crack tip and the evolutions of the SIF at different loading stages can be obtained numerically from the Norton-Bailey model and the $J$-integral method. According to these results, the following conclusions can be obtained. 
(1) The experimental results indicated that the initial cracking and peak loads of the concrete

specimens subjected to creep and creep recovery slightly increased compared with those in the quasi-static tests. For the creep recovery specimens, the initial cracking and peak loads gradually decreased during the recovery stage. The loading history did not show significant influence on the fracture energy of concrete.

(2) By combining with the Norton-Bailey model, the variations of the nominal stress at the crack tip of concrete in the creep and creep recovery processes and the following quasi-static TPB tests were simulated numerically. During the creep stage, the front region of the crack tip was in tension and the stress exponentially decreased due to the occurrence of stress relaxation. The pressure stress generated at the crack tip during recovery duration and its relaxation over the time contributed to the increase of the recovery of creep deformation. In the following quasi-static TPB loading tests, the pressure stress could be covered, leading to the increases of the initial cracking and peak loads.

(3) The numerical simulations indicated that the initial cracking and peak loads of the concrete specimens subjected to the creep and creep recovery stages obtained from the experimental investigations can be divided into two parts. One part of the initial cracking and peak loads was used to induce the pressure stress at the end of the creep recovery stage, while the other part contributed to the crack initiation and unstable crack propagation.

(4) Considering the influence of loading history, the loadings actually contributing to the crack initiation and unstable crack propagation were adopted to calculate the initial and unstable fracture toughnesses of the creep and creep recovery specimens based on the LEFM theory. The values of the initial and unstable fracture toughnesses for the creep and creep recovery specimens were similar to those under quasi-static conditions, indicating that they can still be considered as the material parameters for assessing the crack initiation and instability of concrete. 
484 The authors gratefully acknowledge the financial support of the National Natural Science

Foundation of China under the grants NSFC 51878117 and NSFC 51478083.

486

487

488

489

490

491

492

493

494

495

496

497

498

499

500

501

502

503

504

505

506

507

508

509

510

511

512

513

514

515

516

517

518

519

520

521

522

\section{Conflict of interest}

The authors declare that they have no conflict of interest.

\section{References}

[1] P. Chen, W. Zheng, Y. Wang, K. Du, W. Chang, Strain recovery model for concrete after compressive creep, Const. Build. Mater. 199 (2019) 746-755.

[2] L. Su, Y.-F. Wang, S.-Q. Mei, P.-F. Li, Experimental investigation on the fundamental behavior of concrete creep, Const. Build. Mater. 152 (2017) 250-258.

[3] M. Docevska, G. Markovski, P. Mark, Experimental investigation on the reversibility of concrete creep under repeating loads, Mater. Struct. 52(4) (2019) 1-16.

[4] S.-Q. Mei, J.-C. Zhang, Y.-F. Wang, R.-F. Zou, Creep - recovery of normal strength and high strength concrete, Const Build Mater. 156 (2017) 175-183.

[5] W. Zheng, C. Tang, Y. Wang, Experimental study on the strain recovery of concrete after creep, J. Test. Eval. 47(2) (2019) 977-986.

[6] P. Rossi, J.L. Tailhan, F. Le Maou, Creep strain versus residual strain of a concrete loaded under various levels of compressive stress, Cem. Concr. Res. 51 (2013) 32-37.

[7] A. Neville, Creep recovery of mortars made with different cements, J. Proc. 56(8) (1959) 167-174.

[8] A.S. Abdul, Creep recovery of prepacked aggregate concrete, J. Mater. Civ. Eng. 4(3) (1992) 320-325.

[9] Y. Huang, L. Xiao, J. Gao, Y. Liu, Tensile creep and unloading creep recovery testing of dam concrete with fly ash, J. Mater. Civ. Eng. 31(5) (2019) 1-7.

[10] W.C. Tang, H.Z. Cui, M. Wu, Creep and creep recovery properties of polystyrene aggregate concrete, Const. Build. Mater. 51 (2014) 338-343.

[11] R. Davies, Some experiments on the applicability of the principle of superposition to the strains of concrete subjected to changes of stress, with particular reference to prestressed concrete, Mag. Concr. Res. 9(27) (1957) 161-172.

[12] Y. Qian, S. Kawashima, Use of creep recovery protocol to measure static yield stress and structural rebuilding of fresh cement pastes, Cem. Concr. Res. 90 (2016) 73-79.

[13] A. Oza, R. Vanderby, R.S. Lakes, Interrelation of creep and relaxation for nonlinearly viscoelastic materials: application to ligament and metal, Rheol. Acta. 42(6) (2003) 557-568.

[14] N.M. Kizito, Experimental validation of relaxation prediction models in concrete, J. Mater. Civ. Eng. 30(11) (2018) 1-14.

[15] Z.P. Bažant, R. Gettu, Rate effects and load relaxation in static fracture of concrete, ACI. Mater. J. 89(5) (1992) 456-468.

[16] W. Dong, J. Li, X. Zhang, B. Zhang, Evolution of SIFs of concrete under sustained loading by considering the effects of stress relaxation, J. Mater. Civ. Eng. 12(31) (2019) 1-9.

[17] E. Denarie, C. Cecot, C. Fluet, Characterization of creep and crack growth interactions in the 
fracture behavior of concrete, Cem. Concr. Res. 36(3) (2006) 571-575.

[18] W. Dong, X. Zhang, B. Zhang, Q. Wu, Influence of sustained loading on fracture properties of concrete, Eng. Fract. Mech. 200 (2018) 134-145.

[19] H. Rong, W. Dong, X. Zhang, B. Zhang, Size effect on fracture properties of concrete after sustained loading, Mater. Struct. 52 (1) (2019) 1-12.

[20] M. Omar, A. Loukili, G. Pijaudier, Y. Pape, Creep-damage coupled effects: Experimental investigation on bending beams with various sizes, J. Materi. Civ. Eng. 21(2) (2009) 65-72.

[21] J. Saliba, A. Loukili, F. Grondin, J.P. Regoin, Experimental study of creep-damage coupling in concrete by acoustic emission technique, Mater. Struct. 45(9) (2012) 1389-1401.

[22] J. Saliba, A. Loukili, F. Grondin, J.P. Regoin, Identification of damage mechanisms in concrete under high level creep by the acoustic emission technique, Mater. Struct. 47(6) (2014) 1041-1053.

[23] R. Vrijdaghs, M. Prisco, L. Vandewalle, Uniaxial tensile creep of a cracked polypropylene fiber reinforced concrete, Mater. Struct. 51(1) (2018) 1-12.

[24] F. Barpi, S. Valente, Creep and fracture in concrete: a fractional order rate approach, Eng. Fract. Mech. 70(5) (2003) 611-623.

[25] F. Barpi, S. Valente, A fractional order rate approach for modeling concrete structures subjected to creep and fracture, Int. J. Solids. Struct. 41(9-10) (2004) 2607-2621.

[26] F.P. Zhou, Time-dependent crack growth and fracture in concrete, Lund University, Lund, 1992.

[27] D. Luzio, Numerical model for time-dependent fracturing of concrete, J. Eng. Mech. 135(7) (2009) 632-640.

[28] National Standard of the People's Republic of China (NSPRC) GB 175-2007: Common Portland Cement, Ministry of Construction of the People's Republic of China, 2007.

[29] W. Dong, Z. Wu, X. Zhou, Calculating crack extension resistance of concrete based on a new crack propagation criterion, Constr. Build. Mater. 38 (2013) 879-889.

[30] S. Xu, H.W. Reinhardt, Determination of double- $K$ criterion for crack propagation in quasi-brittle fracture, Part I: Experimental investigation of crack propagation, Int. J. Fract. 98(2) (1999) 111-149.

[31] S. Xu, Y. Zhu, Experimental determination of fracture parameters for crack propagation in hardening cement paste and mortar, Int. J. Fract. 157(1) (2009) 33-43.

[32] H. Kraus, Creep Analysis, New York, ASME Press, 1980.

[33] T. Naoki, Y. Kariya, Y. Kanda, Fatigue life and fracture behavior of micro size Sn-Ag-Cu solder joint, Proc ASME 2011 Pacific Rim Technical Conference and Exhibition on Packaging and Integration of Electronic and Photonic Systems, ASME Press, 2011.

[34] H. Beushausen, C. Masuku, P. Moyo, Relaxation characteristics of cement mortar subjected to tensile strain, Mater. Struct. 45(8) (2012) 1181-1188.

[35] E. Hamed, Relaxation behavior of concrete under sustained uniaxial compressive deformation, J. Mater. Civ. Eng. 28(6) (2016) 1-7.

[36] I.L. Al-Qadi, P.J. Yoo, M.A. Elseifi, S. Nelson, Creep behavior of hot-mix asphalt due to heavy vehicular tire loading, J. Eng. Mech. 135(11) (2009) 1265-1273.

[37] J.R. Rice, Elastic fracture mechanics concepts for interfacial cracks, J. App. Mech. 55 (1988) 98-103.

[38] RILEM, Determination of fracture parameters $\left(K_{\mathrm{Ic}}^{\mathrm{S}}\right.$ and $\left.\mathrm{CTOD}_{\mathrm{c}}\right)$ of plain concrete using three-point bend tests. TC 89-FMT Fracture mechanics of concrete-test methods, Mater. Struct. 23(6) (1990) 457-460. 